\title{
IMPACT OF MANAGEMENT DECISIONS BASED ON MANAGERIAL COMPETENCIES AND SKILLS DEVELOPED TROUGH BIM TECHNOLOGY ON PERFORMANCE OF CONSTRUCTION ENTERPRISES
}

\author{
${ }^{1}$ Tomáš MANDIČÁK, ${ }^{2}$ Peter MESÁROŠ, ${ }^{3}$ Matúč TKÁČ \\ 1,2,3 Department of Construction Technology and Management, Faculty of Civil Engineering \\ Technical University of Kosice, Vysokoskolska 4, 04200 Kosice, Slovakia \\ e-mail: ${ }^{1}$ tomas.mandicak@tuke.sk, ${ }^{2}$ peter.mesaros@tuke.sk, ${ }^{3}$ matus.tkac@tuke.sk
}

Received 31 December 2017; accepted 16 April 2018

\begin{abstract}
Management of construction enterprises requires experience or managerial competencies. To achieve successful results of construction enterprises and projects, for example as cost reducing, increasing revenues, shortening construction time, both are necessary. Building information modeling represents technology for developing of managerial skills for managers. Main aim of research is to analyze and quantify the management decisions based on managerial competencies developed through building information modeling on results of construction enterprises in Slovakia. Cost reducing, increasing of revenues and shortening construction time are main monitored by enterprise and project results. Research hypotheses are based on the assumption that building information modeling has a positive impact on development of managerial competencies and skills and manager's t decisions.
\end{abstract}

Keywords: Management decisions, Managerial competencies and skills, Building information modeling technology

\section{Introduction and problem statement}

The construction industry plays an important role in national economics, contributing significantly to countries' socio-economic situations, Gross Domestic Product (GDP), and employment ratios [1]. The construction industry presents one of the most valuable sectors in the economy [2]. Current times require decision-making based on relevant information and experience of managers in every field. Information and communication technologies are a good tool for collection and use of relevant information for decision-making, generally. Management of construction enterprises also requires experience or managerial competencies [3]. To achieve successful 
performance of construction enterprises and projects, for example cost reducing, increasing revenues, shortening construction time, both are necessary. Building Information Modeling (BIM) is increasingly getting into the awareness in the construction industry. BIM is the process of creating and managing data about the building during its life cycle. BIM has become a part of management tools in modern construction enterprises. BIM represents technology for developing of managerial skills for managers [3]. Based on these facts, there are several questions: What is the use level of BIM in construction enterprise? How big is impact of BIM technology on development of managerial competencies and skills? What is impact of managerial competencies and skills on enterprise results? What are differences in results of construction enterprises (revenues, cost savings and shortening construction time) with BIM using?

After asking these basic questions, there is space for clarifying the observed business results. This is a somewhat greater problem and defining these categories is a more complicated process. The observed results can be considered as profit, sales, profitability indicators and the like. But in the construction industry the situation is different. Of course, these basic indicators can also be compared, but in the context of BIM technologies, the cost-saving indicator and shortening construction time in terms of profitability are important.

\section{Development of managerial competencies through BIM technology}

Managers and their managerial competencies could affect to the competitiveness and economic performance of each company [4]. Managerial competences have been examined in several countries worldwide. According to the European Commission's survey, the largest requirements are for working with data and knowledge [5]. Generally, a few researches point to the need for effective work with the data. It is necessary for proper decision making on the basis of relevant information. Extensive research was conducted in the United Kingdom in January two years ago [6]. Research was realized by Department for Business innovation and Skills of United Kingdom. This research answered on questions as: What is the current demand for digital skills across the economy and what are the different types of digital skills requirements? According this research, the use of digital channels also improves the way public services are delivered at the national and local levels [5], [6]. Capgemini Consulting claims that $90 \%$ of companies said lack digital and managerial skills of their managers [7]. In spite of this fact, only $46 \%$ of companies are investing in developing digital and managerial skills. From this research is known that, existing efforts to develop skills are out of sync only $4 \%$ of enterprises align their training efforts with their digital strategy. Almost $77 \%$ of small and medium-sized enterprises in United Kingdom are having not basic digital skills [6]. Based on research conducted by the Department for Business innovation and Skills of United Kingdom, 35\% percent of construction companies began to provide training for the acquisition of digital competence in new technology. The acquisition of information for correct decision making is in disputable. Based on multiple researches, BIM technology helps to collect and work with building project information [3]. This allows for greater managerial competencies for managers. 
BIM technology represents tool that can positively affect to increasing digital and managerial skills by using. In the context of construction industry, BIM means the process of delivering assets using well-structured digital information that all the necessary parties have access to this digital information. It has all the necessary for participants or stakeholders [8]. The term building information modeling is increasingly getting into the awareness in construction industry. The first mention of the BIM concept was recorded in 2002. Very often, the concept of BIM is perceived as a computer program or a $3 \mathrm{D}$ model that is only part of it. BIM concept has several definitions [9]. Building information modeling is the process of creating and data managing about the building during its life cycle. According to National Institute of Building Science (NIBS) [10], digital model represents a physical and functional object with its characteristics and specifics. It serves as an open database of information about the object for its execution and construction in all lifecycle. BIM is an organized approach to the collection and use of information in construction projects. A digital model contains image and inscription information on the design, construction and maintenance of the building. It is at the center of this effort. Another group of authors thinks BIM is a tool for generating and managing building data through the use of Computer Aided Design (CAD) and Information and Communication Technologies (ICTs). A BIM contains spatial information, material properties and allows different actors to exchange and update information. However BIM was used mainly as visualization and organization tool by the stakeholders of Architecture, Engineering and Construction (AEC) industry in the past, today the purpose of using BIM has changed and it is utilized as a process to improve the performance through the whole life cycle of buildings [11].

In recent years, the adoption of BIM in the AEC industry has been widely advocated. BIM is a verb or an adjective phrase to describe tools, processes and technologies that are facilitated by digital, machine readable documentation about a building, its performance, its planning, its construction and later its operation [12]. Davies and Harty [13] elaborate that BIM has become a common nomenclature for the family of technologies and related practices used to represent and manage the information used for, and created by, the process of designing, constructing and operating buildings. BIM has been developed to facilitate the life-cycle management of buildings. For example, BIM has been used to improve the quality of design [14], [15], to reduce construction cost and delay [16], [17], to ameliorate facilitate management [17], [18], [19] and to facility AEC education in the universities [15], [20], [21], [22]. It is true especially in time, when technical development times are constantly growing shorter, whereas the rate of development is increasing exponentially [23]. BIM technology can be a useful tool for smart building planning too [24].

\section{Methodology}

\subsection{Research aim, data collection and data processing}

The problem statement has been briefly described in the introduction. This stems from the analysis of a number of literatures and the real environment and the needs of 
the construction industry. It is a general assumption that decisions acquired through managerial competencies and skills are better than intuitive management. BIM technology offers a lot of the necessary information and data that are the basis for managerial competencies and skills and this also results in better decision making. Therefore, after a thorough analysis of the problem, the research aim was based on the research questions from the introduction of the contribution. Main aim of research is to analyze and quantify the impact of management decisions based on managerial competencies developed through BIM on results of construction enterprises in Slovakia.

Data collection is a basic step in conducting research and drawing conclusions. Given the nature of the research and the need for research data, the questionnaire was a more desirable tool for data collection. The questionnaire was on-line, where unique filling was provided based on an Internet Protocol (IP) address resolution by the system. This ensured that the respondent could fill in the questionnaire only once. On the other hand, it has to be said that the data collection was anonymous. The selection of enterprises was random and represented of all size groups of construction companies in Slovakia.

Data processing took place in the MS Excel and Statistica version 12 software environment. The first task was to separate the data and assign its values to individual research groups and respondents. Respondents were asked to determine the so-called level of impact of using BIM technologies on management decisions based on managerial competencies and skills. The level should be evaluated on the basis of the Liker scale (from 1 - minimal impact to 5 - maximal impact). The next step was to make an arithmetic mean (average value) for each research group and get a representative impact. This value may point to a trend in this issue. It is an important view of splitting a research sample based on the use of BIM technology. The most important part of data processing is based on the Kruskal-Wallis test [25]. It was tasked to confirm the findings and statistical significance of findings for each research group. This was calculated on the basis of formula [25], ]26],

$$
H=\frac{12}{N(N+1)} \sum_{i=1}^{g} n_{i} r_{i}-3(N+1),
$$

where $n_{i}$ is the number of observations in group; $r_{i}$ is the rank (among all observations) of observation $j ; N$ is the total number of observations across all groups; $H$ is the value of statistically significance.

\subsection{Research sample}

The research sample was made up of all participants in the construction project. The survey involved contractors, sub-contractors, designers and investors. Research sample includes 55 participants of construction projects in Slovakia in difference enterprise size. More detailed described research sample is in Table I. The contractor has the largest representation (50.91\%). Enterprise size is another point of view. Nearly 9\% were large enterprises. Others were Small and Medium-sized Enterprises (SMEs). Enterprise owner (or use of private equity) was last point of view on research sample. 
Table I

Research sample

\begin{tabular}{|l|c|l|}
\hline \multicolumn{1}{|c|}{ Research sample } & Number of participants & \multicolumn{1}{c|}{$\%$} \\
\hline Participants of construction projects & 55 & 100 \\
Contractor & 28 & 50.91 \\
Sub-contractor & 14 & 23.64 \\
Designer & 9 & 18.18 \\
Investor & 4 & 7.27 \\
Enterprise size & 55 & 100 \\
Large enterprises & 7 & 8.24 \\
Medium-sized enterprises & 23 & 27.06 \\
Small enterprises & 27 & 31.76 \\
Microenterprises & 28 & 32.94 \\
Enterprise owner (use of private equity) & 55 & 100 \\
Use foreign private equity & 44 & 80.00 \\
Use only Slovak private equity & 11 & 20.00 \\
\hline
\end{tabular}

\subsection{Hypotheses}

Research hypotheses are based on the assumption that BIM technology has a positive impact on development of managerial competencies and skills, manager's right decisions also. This can lead to lower costs, increase revenue and reduce the time of construction. This research also tries to quantify this impact. Main hypothesis of the research was set as:

$\mathrm{H}$ : Decisions based on managerial competencies and skills developed through BIM technology have impact on construction enterprises results.

This main hypothesis was extended about:

H1: Decisions based on managerial competencies and skills developed through BIM technology have impact on revenues of construction enterprises;

H2: Decisions based on managerial competencies and skills developed through BIM technology have impact on cost savings of construction enterprises;

H3: Decisions based on managerial competencies and skills developed through BIM technology have impact on shortening construction time of construction projects.

\section{Results}

Hypothesis 1: Decisions based on managerial competencies and skills developed through BIM technology have impact on revenues of construction enterprises.

Impact level of enterprises without BIM technology was 2.76 . It is very low value and it is not a significant impact on revenues. Very similar results are for research group with using BIM technology. This research group achieved value at 2.87. These results are possible to see in Fig. 1 . 


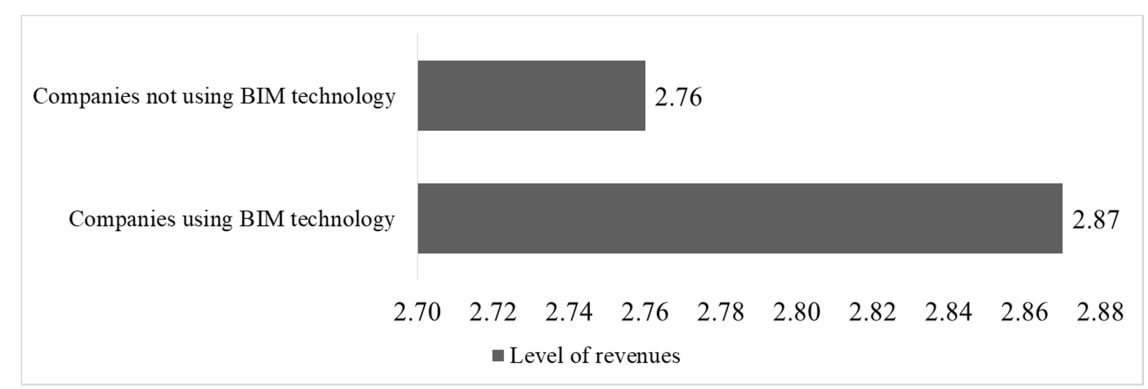

Fig. 1. Impact level of BIM technology on revenues in Slovak construction enterprises

Results of Kruskal-Wallis's anova and results are described in Table II. KruskalWallis test not confirmed based on statistical significance $\alpha=0.05$ (where $\alpha$ represents the significance level and $p$ is the probability), Hypothesis 1. Based on this results it is not possible exactly stated that decisions based on managerial competencies and skills developed through BIM technology have impact on revenues of construction enterprises.

\section{Table II}

Kruskal-Wallis test for Hypothesis 1

\begin{tabular}{|l|c|c|c|}
\hline & \multicolumn{3}{|c|}{$\begin{array}{l}\text { Kruskal-Wallis anova based on ranking, } \\
\text { variable - revenues, } p=0.5342\end{array}$} \\
\hline & Code & $\begin{array}{c}\text { Number of } \\
\text { valid responses }\end{array}$ & Use level \\
\hline Companies not using BIM technology & 1 & 44 & 2.76 \\
Companies using BIM technology & 2 & 11 & 2.87 \\
\hline
\end{tabular}

Hypothesis 2: Decisions based on managerial competencies and skills developed through BIM technology have impact on cost savings of construction enterprises.

Situation in this case is absolutely different. Enterprises not using BIM technology achieved impact level at 2.58. It is not a significant impact on cost savings. On the other side, it is big difference for enterprises with BIM technology. They achieved impact level 4.52 and it means a significant impact. Detailed results can be seen in Fig. 2.

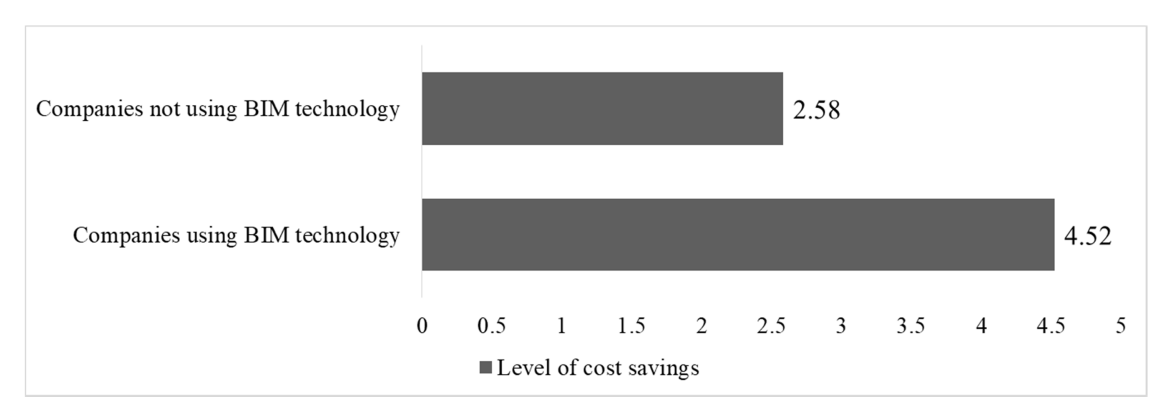

Fig. 2. Impact level of BIM technology on cost savings in Slovak construction enterprises 
Results of Kruskal-Wallis's anova for this hypothesis are described in Table III. Kruskal-Wallis test confirmed based on statistical significance $\alpha=0.05$, Hypothesis 2 . Value of $p=0.0372$, and it can be said, that decisions based on managerial competencies and skills developed through BIM technology have impact on cost savings of construction enterprises.

\section{Table III}

Kruskal-Wallis test for Hypothesis 2

\begin{tabular}{|l|c|c|c|}
\hline & \multicolumn{3}{|c|}{ Kruskal-Wallis anova based on ranking, } \\
& variable - cost savings, $p=0.0372$ \\
\hline & Code & $\begin{array}{c}\text { Number of } \\
\text { valid responses }\end{array}$ & Use level \\
\hline Companies not using BIM technology & 1 & 44 & 2.58 \\
Companies using BIM technology & 2 & 11 & 4.52 \\
\hline
\end{tabular}

Hypothesis 3: Decisions based on managerial competencies and skills developed through BIM technology have impact on shortening construction time of construction projects.

Impact level of enterprises without BIM technology was 2.49. It is very low value and it is not a significant impact on shortening construction time of construction projects. Different results are for research group with using BIM technology. This research group achieved value at 4.36. These results are possible to see in Fig. 3.

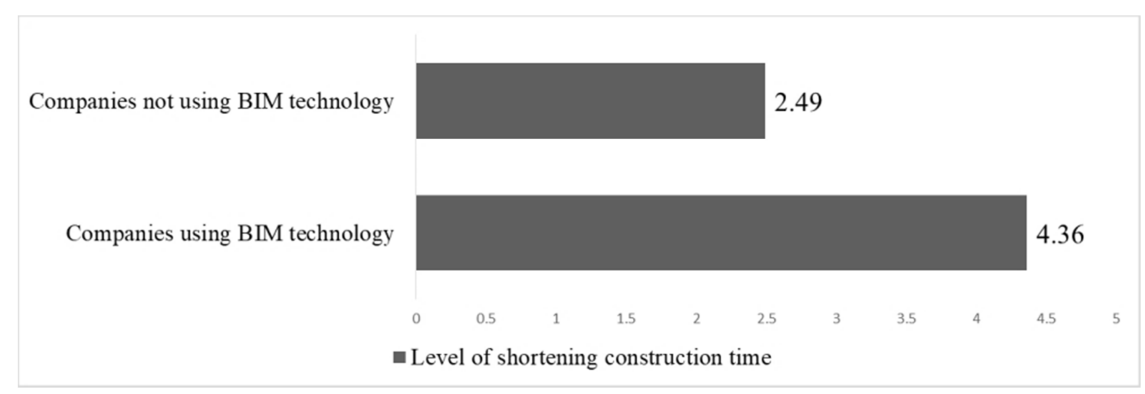

Fig. 3. Impact level of BIM technology on shortening construction time of construction projects in Slovakia

Kruskal-Wallis test for this hypothesis are described in Table IV. Kruskal-Wallis test confirmed based on statistical significance $\alpha=0.05$ Hypothesis 3 . It achieved value of $p=0.0396$ and it can be said, that decisions based on managerial competencies and skills developed through BIM technology have impact on shortening construction time of construction projects.

Generally, BIM technology has a positive impact on decisions making based on managerial competencies skills. Two form three sub-hypotheses were confirmed by Kruskal-Wallis test. These results shown trend of BIM impact and its positive impact on management decisions. BIM technology based on plenty of information and data for is a 
good tool for development of managerial competencies and skills. It claims final results which are described in Table $V$.

Table IV

Kruskal-Wallis test for Hypothesis 3

\begin{tabular}{|l|c|c|c|}
\hline & \multicolumn{3}{|l|}{$\begin{array}{l}\text { Kruskal-Wallis anova based on ranking, } \\
\text { variable - shortening of construction time, } \\
\mathrm{p}=0.0396\end{array}$} \\
\hline & Code & $\begin{array}{c}\text { Number of } \\
\text { valid responses }\end{array}$ & Use level \\
\hline Companies not using BIM technology & 1 & 44 & 2.49 \\
Companies using BIM technology & 2 & 11 & 4.36 \\
\hline
\end{tabular}

Table $V$

Final results of Kruskal-Wallis tests

\begin{tabular}{|l|c|c|c|}
\hline \multicolumn{1}{|c|}{ Hypotheses } & Factor & $\begin{array}{c}\text { K-W } \\
\text { anova (p) }\end{array}$ & $\begin{array}{c}\text { Acceptance/ } \\
\text { rejection }\end{array}$ \\
\hline $\begin{array}{l}\text { H1: Decisions based on managerial } \\
\text { competencies and skills developed } \\
\text { through BIM technology have impact on } \\
\text { revenues of construction enterprises }\end{array}$ & $\begin{array}{l}\text { BIM based } \\
\text { managerial } \\
\text { decisions }\end{array}$ & 0.5342 & Rejected \\
\hline $\begin{array}{l}\text { H2: Decisions based on managerial } \\
\text { competencies and skills developed } \\
\text { through BIM technology have impact on } \\
\text { cost savings of construction enterprises }\end{array}$ & $\begin{array}{l}\text { BIM based } \\
\text { managerial } \\
\text { decisions }\end{array}$ & 0.0372 & Accepted \\
\hline $\begin{array}{l}\text { H3: Decisions based on managerial } \\
\text { competencies and skills developed } \\
\text { through BIM technology have impact on } \\
\text { shortening construction time of } \\
\text { construction projects. }\end{array}$ & $\begin{array}{l}\text { BIM based } \\
\text { managerial } \\
\text { decisions }\end{array}$ & 0.0396 & Accepted \\
\hline $\begin{array}{l}\text { H: Decisions based on managerial } \\
\text { competencies and skills developed } \\
\text { through BIM technology have impact on } \\
\text { construction enterprises results. }\end{array}$ & Generally & & Accepted \\
\hline
\end{tabular}

\section{Conclusion}

The issue of BIM technology and its impact on management decisions based on managerial competencies and skills is highly up to date problem in construction industry. Research has shown the impact of BIM technology on management decisions and development of managerial competencies and skills. Especially, the impact was confirmed in cost savings and shortening of construction time. Based on this, it is new opportunity for extended research in this issue comparing these results with other countries as Hungary, Poland and the Czech Republic, where the nature of the economy is similar to Slovak conditions. On the other hand, it may be very interesting to compare 
these results with more advanced countries in Western Europe and the world. In any case, similar research needs to be done to better understand and use BIM and thus to improve the competitive environment and quality in construction. It is precisely the question of comparison that may be the place where this research will move further for global significance.

\section{Acknowledgements}

The paper presents a partial research results of project VEGA 1/0828/17 'Research and application of knowledge-based systems for modeling cost and economic parameters in Building Information Modeling'.

\section{References}

[1] Rashidi A., Rahinah I. Industrialized construction chronology: The disputes and success factors for a resilient construction industry in Malaysia, The Open Construction and Building Technology Journal, Vol. 11, 2017, pp. 286-300.

[2] Mandicak T., Mackova D., Mesaros P., Spisakova M. Impact model of communication and marketing tools for the promotion of family houses built by modern methods of construction, International Journal of Applied Engineering Research, Vol. 12, No. 21, 2017, pp. 11749-11759.

[3] Mesaros P., Mandicak T., Mesarosova A., Behún M. Developing managerial and digital competencies trough BIM technologies in construction industry, ICETA 2016 - 14th IEEE International Conference on Emerging eLearning Technologies and Applications, StarySmokovec, The High Tatras, 24-25 November, 2016, pp. 217-222.

[4] Štrba L., Kršák B., Sidor C., Blišt’an P. Destination business information systems for smart destinations: the case study of Kosice country, International Journal of Business and Management Studies, Vol. 5, 2016, pp. 177-180.

[5] Ferrari A. Digital competence in practice: an analysis of frameworks, Technical Reports, Joint Research Center of the European Commission, 2012.

[6] Digital skills for UK economy, Department for Business Innovation and Skills, 2016.

[7] The digital talent gap - developing skills for today's digital organizations, Capgemini Comsulting, 2013.

[8] Kreider R. G., Messner J. I. The uses of BIM - classifying and selecting of BIM uses, 2013

[9] Černý M. BIM handbook, (in Slovak) Praha, 2013.

[10] NIST 7417, National building information modeling standard, US, National Institute of Building Science, Washington, DC, 2007.

[11] Lu W., Peng Y., Shen Q., Ling H. Generic model for measuring benefits of BIM as a learning tool in construction tasks, Journal of Construction Engineering and Management, Vol. 139, No. 2, 2012, pp. 195-213.

[12] Eastman C., Teicholz P., Sacks R., Liston K. BIM handbook: a guide to building information modeling for owners, managers, designers, engineers and contractors, 2nd ed. John Wiley and Sons, New Jersey, 2011.

[13] Davies R., Harty C. Measurement and exploration of individual beliefs about the consequences of building information modeling use, Construction Management and Economics, Vol. 31, No. 11, 2013, pp. 1110-1127. 
[14] Kaner I., Sacks R., Kassian W., Quitt T. Case studies of BIM adoption for precast concrete design by mid-sized structural engineering firms, Journal of Information Technology in Construction, Vol. 13, 2008, pp. 303-323.

[15] Sacks R., Barak R. Impact of three-dimensional parametric modeling of buildings on productivity in structural engineering practice, Journal Automation in Construction, Vol. 17, No. 4, 2008, pp. 439-449.

[16] Azhar S., Hein M., Sketo B. Building information modeling (BIM): benefits, risks and challenges, Leadership and Management in Engineering, Vol. 11, No. 3, 2011, pp. 241-252.

[17] Lu W. S., Peng Y., Shen Q., Li H. A generic model for measuring benefits of BIM as a learning tool in construction works, Journal of Construction Engineering and Management, Vol. 139, No. 2, 2013, pp. 195-203.

[18] Morton J. BIM - The intelligent choice for O\&M, Build, Vol. 105, No. 8, 2011, pp. 32-36.

[19] Lawrence T. M., Watson R. T., Boudreau M. C., Johnsen K., Perry J., Ding L. A new paradigm for the design and management of building systems, Energy and Building, Vol. 51, 2012, pp. 56-63.

[20] Hedges K. E., Denzer A. S. How a collaborative architecture influences structural engineering education, Proceedings of Structures Congress, Vancouver, British Columbia, 24-26 April 2008, pp. 25-33.

[21] Peterson F., Hartmann T., Fruchter R., Fischer M. Teaching construction project management with BIM support: experience and lessons learned, Automation in Construction, Vol. 20, No. 2, 2011, pp. 115-125.

[22] Mitchell D. 5D BIM: Creating cost certainty and better buildings, Proceedings of the 19th CIB World Building Congress, Brisbane, 5-9 May 2013, pp. 74-85.

[23] Werner J. Architecture and design, flexible building construction, Pollack Periodica, Vol. 11, No. 1, 2016, pp. 163-174.

[24] Baranyai B., Póth B., Kistelegdi I. Planning and research of smart buildings and constructions with energy design roadmap method, Pollack Periodica, Vol. 8, No. 3, 2013, pp. 15-26.

[25] Kruskal W. H., Wallis W. A. Use of ranks in one-criterion variance analysis, Journal of the American Statistical Association, Vol. 47, No. 260, 1952, pp. 583-621.

[26] Corder G. W., Foreman, D. I. Nonparametric statistics for non-statisticians: A step-by-step approach, John Wiley, 2009, pp. 99-105. 